д.э.н., профессор кафедры маркетинга и экономики ЧОУ ВО «Казанский инновационный университет имени В.Г. Тимирясова (ИЭУП)», e-mail: galeeva@nzh.ieml.ru

\title{
DOI:10.26726/1812-7096-2021-5-149-156 \\ ОПТИМИЗАЦИЯ НАЛОГОВОЙ НАГРУЗКИ КОММЕРЧЕСКОЙ ОРГАНИЗАЦИИ
}

Аннотауия. Цель работы. В статье рассматриваются способы оптимизации налоговой нагрузки коммерческой организации. Методология проведения работы. Для достижения поставленной цели необходимо решить ряд задач, связанных с сущностью налоговой нагрузки организации, методами ее оценки и анализом, выявлением проблем налогообложения организащии и определением путей их решения. В процессе исследования были использованы различные научные методы: философские, общенаучные, теоретические, абстрактно-логические, исторические, эмпирические. Результаты работы. Налоговые пла-

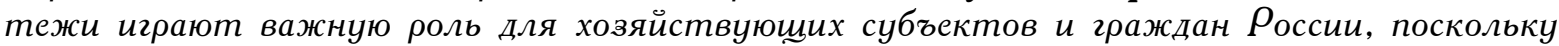
оценка налоговых обязательств даёт возможность определить, насколько обременительна для них действующая в стране налоговая система и какая часть их ресурсов тоатится на выплаты в бюджеты различных уровней. В работе обобщены взгляды различных ученых на сущиность понятия «налоговая нагрузка» организации, рассмотрены методики оценки налоговой нагрузки, проведен анализ налоговой нагрузки организации на примере ООО «Управляющая компания “Мой дом Камских полян”», выявлены проблемы налогообложения организаиии, определены пути их решения. Область применения. $\rho_{e-}$ зультаты работы могут быть использованы как в практике работы исследуемой орга-

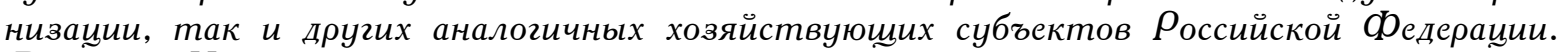
Выводы. Необходимо отметить, что оптимизация налогообложения коммерческой организации должна проводиться до официальной регистрации субъекта экономической деятельности, так как в момент регистращии выбирается будущий налоговой режим данного субъекта. Если в момент регистрации не был решён вопрос оптимизащии налоговой нагрузки, то в проиессе хозяйственной деятельности организаиии следует обратить внимание на структуру издержек и оставляемую после налогообложения прибыль. Часто складывается такая ситуаџии, что структура налогообложения хозяйствующего субъекта выстроена не оптимально и формирует недополученную прибыль собственников. Поэтому субъектам предпринимательства необходимо учитывать как правовую,

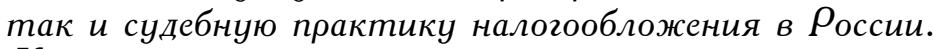

Ключевые слова: налогообложение организации, налоговая нагрузка, анализ налоговой нагрузки, оптимизация налогообложения.

GALEEVA EVGENIYA ISAEVNA

Dr.Sc. of Economics, Professor of the Department of Marketing and Economics, Kazan Timiryasov Innovation University (IEPU), e-mail: galeeva@nzh.ieml.ru

\section{OPTIMIZATION OF THE TAX BURDEN OF A COMMERCIAL ORGANIZATION}

Abstract. The purpose of the work. The article discusses ways to optimize the tax burden of a commercial organization. Methodology of the work. To achieve this goal, it is necessary to solve a number of tasks related to the essence of the tax burden of the organization, methods of its assessment and analysis, identifying the problems of taxation of the organization and determining ways to solve them. In the course of the research, various scientific methods were used: philosophical, general scientific, theoretical, abstract-logical, historical, empirical. The results of the work. Tax payments play an important role for economic entities and citizens of Russia, since the assessment of tax liabilities makes it possible to determine how burdensome the current tax 
system in the country is for them and how much of their resources are spent on payments to budgets of various levels. The paper summarizes the views of various scientists on the essence of the concept of "tax burden" of the organization, considers the methods of assessing the tax burden, analyzes the tax burden of the organization on the example of LLC "Management Company "My house of Kamsky Polyans"", identifies the problems of taxation of the organization, identifies ways to solve them. Scope of application. The results of the work can be used both in the practice of the organization under study, and other similar economic entities of the Russian Federation. Conclusions. It should be noted that the optimization of taxation of a commercial organization should be carried out before the official registration of the subject of economic activity, since at the time of registration the future tax regime of this subject is selected. If the issue of optimizing the tax burden was not resolved at the time of registration, then in the course of the organization's economic activity, attention should be paid to the cost structure and the profit left after taxation. Often there is such a situation that the structure of taxation of an economic entity is not built optimally and forms the lost profit of the owners. Therefore, business entities need to take into account both the legal and judicial practice of taxation in Russia.

Введение. Налоги, как и вся налоговая система, являются мощным инструментом управления экономикой в условиях рынка. Государство широко использует налоговую политику в качестве определенного регулирующего воздействия на негативные явления рынка. От того, насколько правильно построена система налогообложения, зависит эффективное функционирование всего народного хозяйства.

Согласно Е.В. Шестаковой, налоговая политика и налогообложение организаций - это главные инструменты, которые обеспечивают функционирование не только бюджетной системы государства и национальной экономической системы, но и степень деловой, производственной и инвестиционной активности хозяйствующих субъектов [15].

По мнению М.Г. Демидовой, налоговая политика государства должна иметь минимальное влияние на развитие бизнеса, принятие их стратегических решений по масштабированию финансово-производственной деятельности. Однако современные условия налоговой политики Российской Федерации характеризуются тем, что создаются предпосылки для роста налоговой нагрузки на финансово-производственную деятельность отечественных предприятий [3].

Налоговые платежи играют важную роль в деятельности хозяйствующих субъектов и граждан, поскольку величина налоговых обязательств даёт возможность определить, насколько обременительна для них действующая в стране налоговая система. Для оценки налоговых обязательств было введено понятие «налоговая нагрузка», упоминание о которой относится еще к XVIII в. Первыми исследователями этого понятия стали западные экономисты, такие, как А. Смит, Ф. Юсти, А. Бифельд и К. Гок и др. [18].

Согласно Е.С. Филипповичу, на протяжении более 200 лет ученые-экономисты достаточно серьезно исследовали вопрос о влиянии налогов на население и экономику в целом. Одновременно ими делались попытки определения обоснованного уровня налогообложения, установления количественной оценки показателя налоговой нагрузки [13].

Под совокупной налоговой нагрузкой в настоящее время понимается отношение суммы налогов и сборов, начисленных за определенный период времени, за исключением сумм акцизов, налога на добавленную стоимость и взносов в Пенсионный фонд Российской Федерации, к выручке от продажи продукции и товаров, а также поступлениям, связанным с выполнением работ и оказанием услуг. Величина налоговой нагрузки определяется в соответствии с правилами бухгалтерского учета за определенный период времени (календарный год, часть календарного года) [8].

Согласно Э.С. Ткачевой и Ю.Н. Харитоновой, «налоговая нагрузка» - это мера, степень, уровень экономических ограничений, создаваемых отчислением средств на уплату налогов и сборов. Её величина зависит в первую очередь от количества и видов налоговых платежей и налоговых ставок [11].

По мнению Е.А. Амелиной, «налоговая нагрузка» является бременем, налагаемым любым обязательным платежом [1], а Зарипова Н.Д. отмечает, что «налоговая нагрузка» - это ком- 
плексная характеристика налоговых платежей организации, которая включает количество налогов и других обязательных платежей, структуру налогов, механизм взимания налогов, показатель налоговой нагрузки на предприятие [4].

«Налоговая нагрузка», как отмечают П.С. Поторочин и М.С. Рябынцева, - один из основных показателей деятельности экономических субъектов, представляющий собой комплексную характеристику, которая включает количество налоговых платежей, их структуру и механизм взимания $[9,10]$.

Налоговая нагрузка может быть абсолютной и относительной. Абсолютная налоговая нагрузка - это общая сумма налоговых платежей, перечисляемых в бюджеты различных уровней. Относительная налоговая нагрузка - это соотношение между суммой уплаченных налоговых платежей и финансовым показателем [2]. Лебедь А.Р. полагает, что налоговую нагрузку в зависимости от уровня ее воздействия принято классифицировать на нагрузку на макро- и микроуровне [6].

Задача налогового регулирования - это, с одной стороны, формирование базы источников налоговых доходов в федеральный, региональные и местные бюджеты, с целью обеспечения

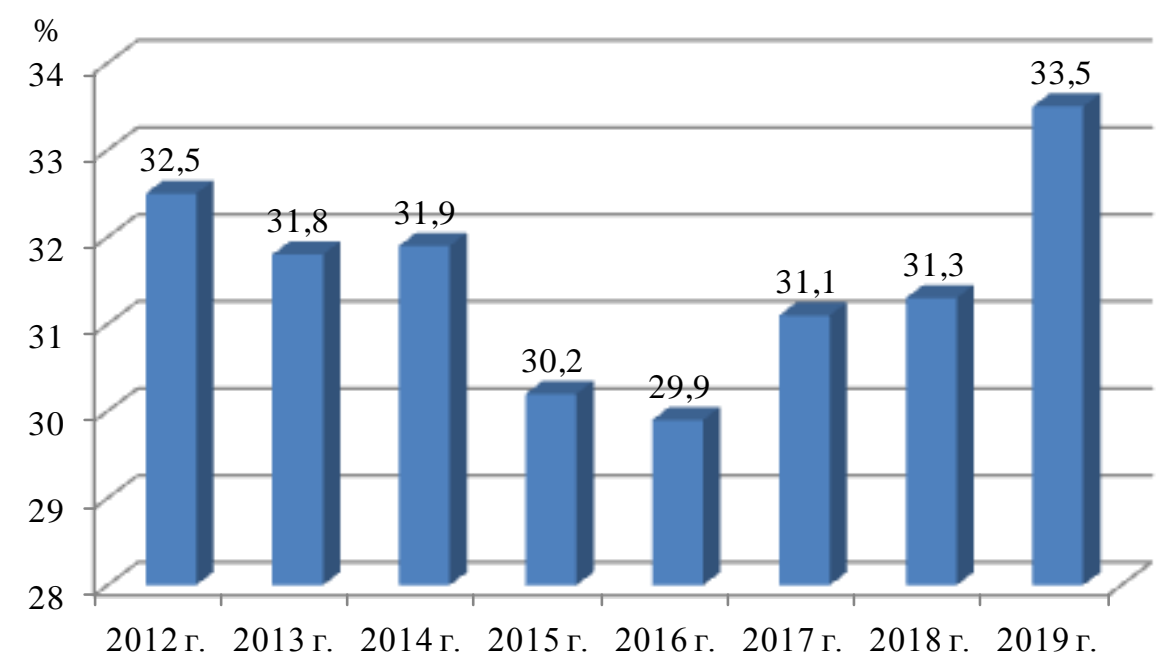

Pис. 1. Динамика налоговой нагрузки организаиий Российской Федерации в период с 2012 по 2019 г2. [3]

На рис. 1 представлена динамика налоговой нагрузки организаций Российской Федерации в период с 2012 по 2019 гг. Согласно данным рис. 1, налоговая нагрузка отечественного бизнеса, начиная с 2012 по 2016 гг. уменьшилась на 2,6\%, а в период с 2016 по 2019 гг. увеличилась.

Такое увеличение налогового бремени приводит к снижению финансовых результатов деятельности организаций, что в дальнейшем ведет к более низким капитальным вложениям в развитие бизнеса и масштабирование производства. Некоторые организации пытаются уклониться от уплаты налогов, поскольку такая налоговая нагрузка угрожает существованию их бизнеса. Данная ситуация побуждает налоговые органы к совершенствованию системы налогообложения, налогового контроля и мониторинга. Задачей оптимизации налоговой политики государства является соблюдение интересов бюджета и частного сектора в равноценных пропорциях.

Мировая практика налогообложения показывает, что нормальным уровнем налоговой нагрузки на хозяйствующий субъект является значение в пределах от 30 до 40\% от суммы его дохода [16].

Однако сами показатели налоговой нагрузки существенно различаются в разных странах мира. Так, экономические исследования Х. Джейсона и Дж. Риоса свидетельствуют о том, что в промышленно развитых государствах закономерен высокий уровень налоговой обременен- 
ности (примерно в два раза) по сравнению со слаборазвитыми странами, где отсутствует система мощного обеспечения в социальной сфере [11].

Согласно проведенным исследованиям, реальная налоговая нагрузка на бизнес в среднем в мире составляет примерно 40,6\%. Уровень налоговой нагрузки в России - около 47,4\%. При этом в 45 странах значение этого показателя гораздо выше, чем в России. Например, в Китае $68 \%$, Франции - 63\%, Италии - 62\%, Мексике - 52\%, Чехии - 50\% [17].

Методы исследования. Для любого субъекта хозяйственной деятельности важно оценить уровень налоговой нагрузки и его динамику под воздействием различных факторов и целенаправленных действий. В настоящее время используют различные методики расчета налоговой нагрузки, авторами которых являются: Министерство финансов РФ [19]; Караман Е.И. [5]; Труфанова Л.В. [12], Харькова Е.С. [14] и др. Достоинством методики Е.С. Харьковой является то, что она позволяет с различной степенью детализации, в зависимости от поставленной задачи, рассчитать налоговую нагрузку для экономических субъектов любых отраслей народного хозяйства.

На наш взгляд, рационально использовать следующую формулу для определения налоговой нагрузки организации (НН) [19]:

$$
\mathrm{HH}=\frac{\sum \mathrm{HБ}_{\mathrm{i}} \cdot \mathrm{C}_{\mathrm{i}}-\sum\left(\frac{\mathrm{6B}}{(1+\mathrm{r})^{\mathrm{n}}}\right)}{\mathrm{B}+\Pi_{\Pi}+\Pi_{д}}
$$

где В - выручка; Пп - проценты к получению; Пд - прочие доходы; НБі - налоговая база по i-му налогу; Сi - ставка по i-му налогу; БВ - бюджетное возмещение; $\mathrm{r}$ - ставка ЦБ РФ; $\mathrm{n}$ количество периодов.

Согласно представленной формуле, рассчитаем налоговую нагрузку для исследуемой организации (на примере ООО «Управляющая компания “Мой дом Камских Полян”»). Данная компания управляет жилищно-коммунальным хозяйством в поселке городского типа Камские Поляны Республики Татарстан. ООО «Управляющая компания “Мой дом Камских Полян”» применяет общий режим налогообложения.

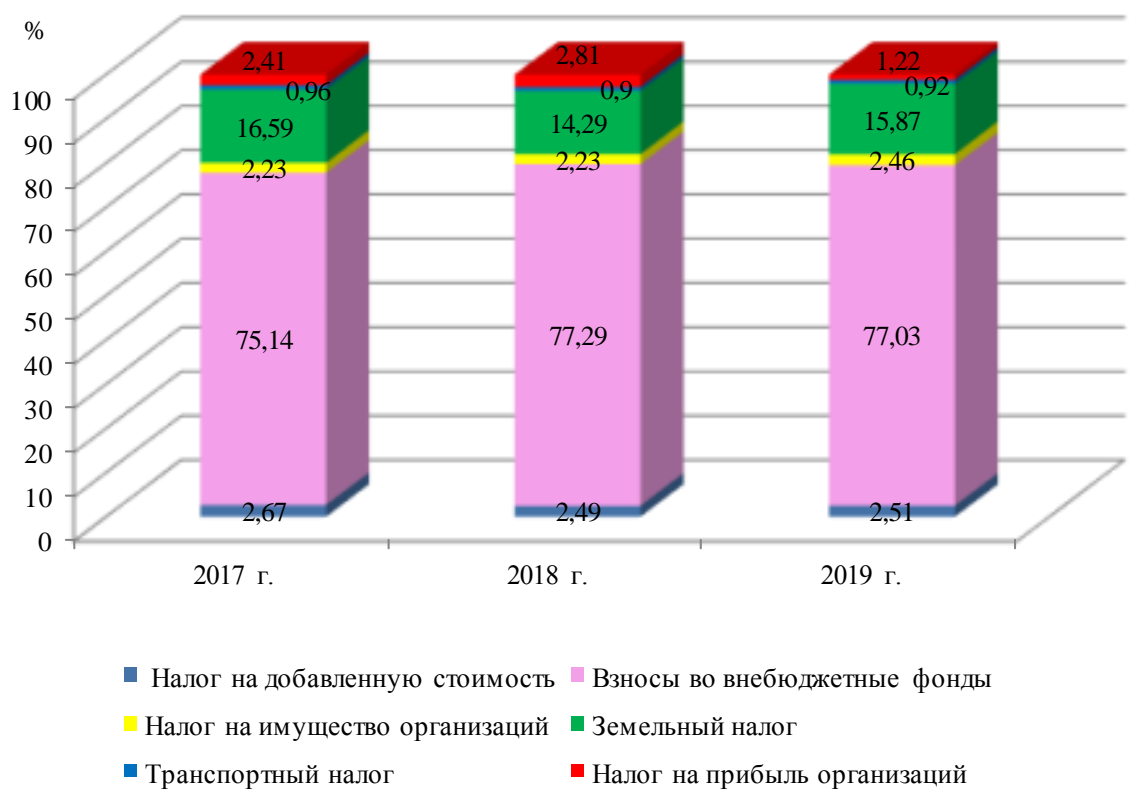

Pис. 2. Структура уплачиваемых налогов ООО «Управляющая компания "Мой дом Камских Полян”» за 2017-2019 г2., \%

Наибольший удельный вес в общей сумме налогов, уплачиваемых организацией за 2017 2019 гг., занимают взносы во внебюджетные фонды. Их удельный вес составляет 75-77\% от 
общей суммы налогов ООО «Управляющая компания “Мой дом Камских Полян”». Также значительный удельный вес занимает земельный налог. В 2017 г. его удельный вес составил 16,59\%, в 2018 г. - 14,29\%, а в 2019 г. - 15,87\%. Налог на добавленную стоимость, налог на прибыль и налог на имущество в ООО «Управляющая компания “Мой дом Камских Полян”» занимают примерно равные доли - от 2,0 до $2,5 \%$.

Нами был проведен расчет налогового бремени исследуемой организации за 2017-2019 гг. по методике Департамента налоговой политики Министерства финансов РФ. Были получены следующие данные: в 2018 г. на один рубль прибыли до налогообложения налоговая нагрузка в ООО «Управляющая компания “Мой дом Камских Полян”» составила 8,36 коп. (или 8,36\%). В 2018 г. по сравнению с 2017 г. данный показатель уменьшился на 1,5\% и составил 6,86\%. Напротив, в 2019 г. по сравнению с 2018 г. он увеличился на 0,11\%.

Налоговая оптимизация - это деятельность, осуществляемая с целью снижения суммы налоговых платежей организации. Первым и наиболее универсальным способом оптимизации является выбор специального налогового режима. Вторым по значимости является метод смены юрисдикции организации. При смене юрисдикции внутри страны хозяйствующий субъект может получить те или иные привилегии в налогообложении.

Одним из эффективных методов оптимизации налоговой нагрузки является использование инструментов налогового планирования [1].

При помощи инструментов налогового планирования руководство организации способно получить следующие преимущества:

1. Минимизировать уровень налогового давления на финансово-производственную деятельность.

2. Увеличить экономическую эффективность и финансовый результат бизнеса.

3. Обеспечить экономическую безопасность и финансовую устойчивость компании.

4. Свести к минимуму риски наложения штрафных санкций со стороны контролирующих органов.

5. Оптимизировать систему управления денежными потоками организации.

Для исследуемой организации основным направлением снижения налоговой нагрузки является оптимизация налога на прибыль путем формирования резерва по сомнительным долгам, который может быть обусловлен суммой обязательств (дебиторской задолженности), которые уже просрочены [7].

Согласно данным бухгалтерской отчетности ООО «Управляющая компания "Мой дом Камских Полян”» за 2019 г. просроченная дебиторская задолженность организации составляет 386 тыс. руб. Следовательно, ООО «Управляющая компания “Мой дом Камских Полян”» может сформировать резерв по сомнительным долгам в сумме 386 тыс. руб., что, в свою очередь, позволит повысить величину рентабельности капитала.

Рентабельности капитала исследуемой организации во времени имеет вид уравнения прямой [15]:

$$
\mathrm{yt}=\mathrm{a}_{0}+\mathrm{a}_{1} \mathrm{t}
$$

Параметры уравнения следующие:

$$
\mathrm{a}_{0}=\frac{\frac{\sum y}{n}}{\mathrm{a}_{1}=} ;
$$

Исходные данные для расчета трендовой модели изменения рентабельности капитала ООО «Управляющая компания “Мой дом Камских Полян”» во времени представлены в табл.

Используя формулы 2-4 и исходные данные табл., определим величины параметров уравнения:

$$
a_{0}=\frac{9,60}{7}=1,3714 ; a_{1}=\frac{\frac{6,59}{28}}{=0,2353 .}
$$


Уравнение прямой будет иметь следующий вид: $\mathrm{yt}=1,3714+0,2353 \mathrm{t}$.

Согласно данному уравнению, прогноз рентабельности капитала ООО «Управляющая компания “Мой дом Камских Полян”» на 2020 г. будет следующим:

$\mathrm{yt}=1,3714+0,2353 \cdot 4=2,31 \%$.

Прогноз рентабельности капитала ООО «Управляющая компания “Мой дом Камских Полян”» на 2021-2025 гг. при инерционном развитии событий примет следующие значения:

2021 г.: $\mathrm{yt}=1,3714+0,2353 \cdot 5+0,54=2,55 \%$;

2022 г.: $\mathrm{yt}=1,3714+0,2353 \cdot 6+0,54=2,78 \%$;

2023 г.: $\mathrm{yt}=1,3714+0,2353 \cdot 7+0,54=3,02 \%$;

2024 г.: yt $=1,3714+0,2353 \cdot 8+0,54=3,25 \%$;

\begin{tabular}{|c|c|c|c|c|}
\hline Год & $\mathrm{t}$ & $\mathrm{t}^{2}$ & $\mathrm{yt}$ & $\mathrm{y}$ \\
\hline 2013 & -3 & 9 & $-1,68$ & 0,56 \\
\hline 2014 & -2 & 4 & $-1,78$ & 1,10 \\
\hline 2015 & -1 & 1 & $-1,10$ & 1,12 \\
\hline 2016 & 0 & 0 & 0 & 2,01 \\
\hline 2017 & 1 & 1 & 2,01 & 2,62 \\
\hline 2018 & 2 & 4 & 5,24 & 1,30 \\
\hline 2019 & 3 & 9 & 3,90 & $\sum \mathrm{y}=9,60$ \\
\hline
\end{tabular}

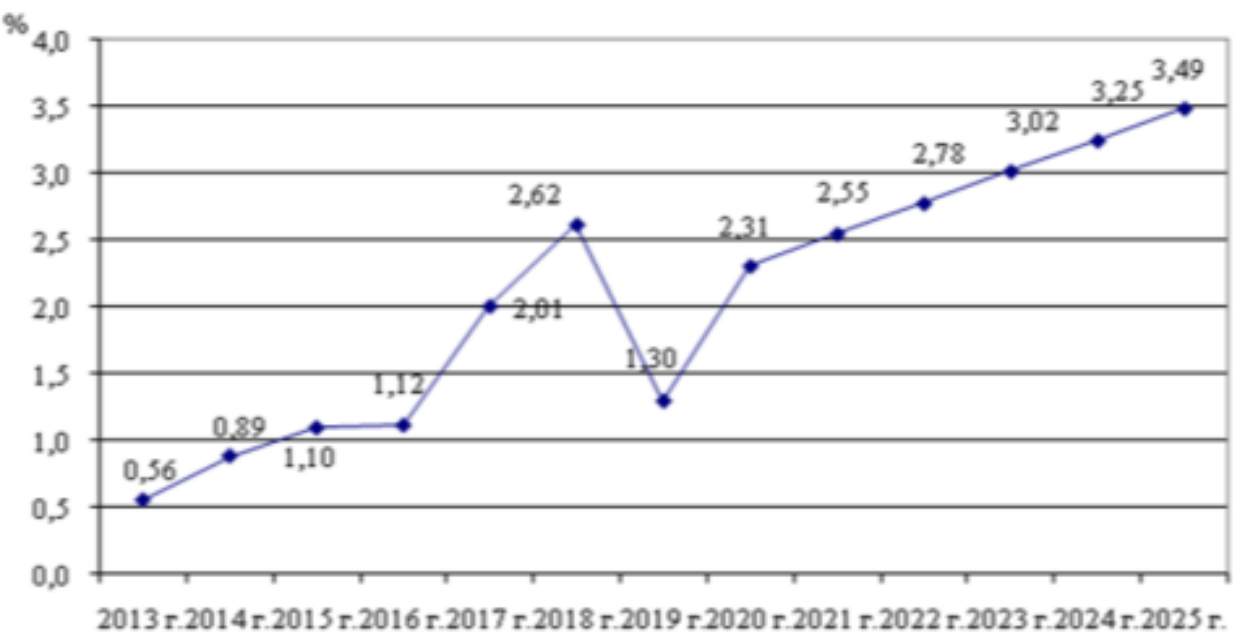

Pис. 3. Динамика рентабельности капитала ООО «Управляющая компания "Мой дом

Камских Полян”» за 2013-2019 г2. и ее прогноз на период с 2020 до 2025 г2.

Согласно данным рис. 3 , при формировании резерва по сомнительным долгам, рентабельность капитала ООО «Управляющая компания “Мой дом Камских Полян”» в 2025 г. увеличится по сравнению с 2019 г. на 2,19\%.

Выводы. Оптимизация налогообложения коммерческих организаций в России - актуальная задача. Важными направлениями оптимизации налогообложения являются: выбор специального налогового режима, смена юрисдикции компании внутри страны либо использование методов оптимизации налоговой нагрузки. Для ООО «Управляющая компания "Мой дом Камских Полян”» предпочтительным является третье направление. Нами разработаны мероприятия, которые оптимизируют налоговую нагрузку в ООО «Управляющая компания “Мой дом Камских Полян”» в 2021-2025 гг. В качестве основного направления оптимизации предложена оптимизация налога на прибыль путем создания в организации резерва по сомнительным долгам. Это мероприятие увеличит сумму чистой прибыли организации в 2020 г/, которую можно будет вложить в расширение производства или модернизацию оборудования. Формирование резерва по сомнительным долгам позволит повысить величину нераспределенной 
Лuтература

1. Амелина, Е.А. Налоговая нагрузка организации : понятие, методики расчета и направления оптимизаичи / Е.А. Амелина // Калужский экономический вестник. 2020. № 2. С. 68-72.

2. Бухадеева, Н. В. Оченка налоговой нагрузки и методические подходы к ее совершенствованию / Н.В. Бухадеева. - СПб. : Питер, 2019.

3. Демидова, М. Г. Проблемные вопросы понятия «налоговая нагрузка» в Российской Федераиии / М.Г. Демидова // Вестник Санкт-Петербургской юридической академии. 2020. № 3 (48). С. 39-43.

4. Зарипова, Н. Д. К вопросу о понятии налоговой нагрузки / Н.Д. Зарипова // Инновачии. Наука. Образование. 2020. № 23. С. 2204-2207.

5. Караман, Е. И. Методика расчета налоговой нагрузки / Е.И. Караман // Вопросы науки и образования. 2020. № 16 (100). С. 10-14.

6. Лебедь, А. Р. Основные подходыл к определению экономической сущности налоговой нагрузки / А.Р. Лебедь // Colloquium-journal. 2020. № 27-2 (79). C. 21-24.

7. Мешкова, Д. А. Налогообложение организаций в Российской Федераџии : учебник для бакалавров / Д. А. Мешкова, Ю. А. Топчи ; под ред. д. э.н., проф. А. З. Дадашева. - М. : Издательско-торговая корпораиия «Дашков и $K^{\circ} », 2018$.

8. Налоговый кодекс РФ. Ч. 2 : Федеральный закон Российской Федерации от 5 августа 2000 2. № 117 Ф3 (с последующими изм.) // Собрание законодательства Российской Федерации. 2000. № 32. Сm. 3340. 9. Поторочин, П. С. Определение налоговой нагрузки и суть её оптимизациии / П.С. Поторочин // Вестник науки. 2020. T. 2. № 1 (22). С. 151-154.

10. Рыбянцев, М. С. Налоговая нагрузка коммерческой организациии и направления её оптимизации / М.С. Рыбянцева, И.А. Струкова // Экономика и бизнес : теория и практика. 2020. № 4-3 (62). С. $25-28$.

11. Ткачева, Э. С. Снижение налоговой нагрузки на предприятии / Э.С. Ткачева, Ю.Н. Харитонова // Инновации. Наука. Образование. 2020. № 24. С. 185-192.

12. Труфанова, Л. В. Налоговая нагрузка и методы её оптимизации / Л.В. Труфанова // Дневник науки. 2020. № 2 (38). C. 22 .

13. Филиппович, Е. С. Вариативность показателя «налоговая нагрузка» в зависимости от предполагаемых иеелей использования / Е.С. Филиппович // Белорусский экономический журнал. 2020. № 1 (90). С. 67 -78 .

14. Харькова, Е. С. Основные подходы к расчету налоговой нагрузки организации / Е.С. Харькова // Моя профессиональная карьера. 2020. T. 1. № 12. С. 209-213.

15. Шестакова, Е. В. Оптимизачия налогов / Е.В. Шестакова. - Ростов /н/Д. : Феникс, 2019.

16. Ault, H. J. Comparative Income Taxation : A Structural Analysis / H.J. Ault. - New York : Arnold B.J. Aspen Publisher, 2018.

17. Feenstra, R. C. Advanced international trade : theory and evidence / R.C. Feenstra. - Princeton : Princeton University Press, 2018.

18. Paart Van der, D. Subsidies in the EU and Switzerland / D. Van der Paart, N.G. Rene // VAT Monitor. IBFD. 2019. № 2. P. 32-36.

19 URL : http://www.nalog.ru - Федеральная налоговая служба (дата обращения : 01.03.2021).

20.URL : http://elibrary.ru - Научная электронная библиотека (дата обращения: 16.04.2021).

\section{References:}

1. Amelina, E.A. Nalogovaya nagruzka organizacii : ponyatie, metodiki rascheta i napravleniya optimizacii

E.A. Amelina // Kaluzhskij ekonomicheskij vestnik. 2020. № 2. S. 68-72.

2. Buhadeeva, N. V. Ocenka nalogovoj nagruzki i metodicheskie podhody $k$ ee sovershenstvovaniyu / N.V. Buhadeeva. - SPb. : Piter, 2019.

3. Demidova, M. G. Problemnye voprosy ponyatiya «nalogovaya nagruzka»v Rossijskoj Federacii / M.G. Demidova // Vestnik Sankt-Peterburgskoj yuridicheskoj akademii. 2020. № 3 (48). S. 39-43.

4. Zaripova, N. D. K voprosu o ponyatii nalogovoj nagruzki / N.D. Zaripova // Innovacii. Nauka. Obrazovanie. 2020. № 23. S. 2204-2207.

5. Karaman, E. I. Metodika rascheta nalogovoj nagruzki / E.I. Karaman // Voprosy nauki i obrazovaniya. 2020. № 16 (100). S. 10-14.

6. Lebed', A. R. Osnovnye podhody k opredeleniyu ekonomicheskoj sushchnosti nalogovoj nagruzki / A.R. Lebed' // Colloquium-journal. 2020. № 27-2 (79). S. 21-24.

7. Meshkova, D. A. Nalogooblozhenie organizacij v Rossijskoj Federacii : uchebnik dlya bakalavrov / D. A. Meshkova, YU. A. Topchi; pod red. d. e.n., prof. A. Z. Dadasheva. - M. : Izdatel'sko-torgovaya korporaciya "Dashkov $i K^{\circ} », 2018$.

8. Nalogovyj kodeks RF. CH. 2 : Federal'nyj zakon Rossijskoj Federacii ot 5 avgusta 2000 g. № 117-FZ (s posleduyushchimi izm.) // Sobranie zakonodatel'stva Rossijskoj Federacii. 2000. № 32. St. 3340.

9. Potorochin, P. S. Opredelenie nalogovoj nagruzki i sut' eyo optimizacii / P.S. Potorochin // Vestnik nauki. 2020. T. 2. № 1 (22). S. 151-154.

10. Rybyancev, M. S. Nalogovaya nagruzka kommercheskoj organizacii i napravleniya eyo optimizacii / M.S. Rybyanceva, I.A. Strukova // Ekonomika i biznes : teoriya i praktika. 2020. № 4-3 (62). S. 25-28.

11. Tkacheva, E. S. Snizhenie nalogovoj nagruzki na predpriyatii / E.S. Tkacheva, YU.N. Haritonova // Innovacii. Nauka. Obrazovanie. 2020. № 24. S. 185-192.

12. Trufanova, L. V. Nalogovaya nagruzka i metody eyo optimizacii / L.V. Trufanova // Dnevnik nauki. 2020. № 2 (38). S. 22.

13. Filippovich, E. S. Variativnost' pokazatelya «nalogovaya nagruzka» v zavisimosti ot predpolagaemyh celej 


\section{ГАЛЕЕВА Е.И.}

ОПТИМИЗАЦИЯ НАЛОГОВОЙ НАГРУЗКИ КОММЕРЧЕСКОЙ ОРГАНИЗАЦИИ

ispol'zovaniya / E.S. Filippovich // Belorusskij ekonomicheskij zhurnal. 2020. № 1 (90). S. 67-78.

14. Har'kova, E. S. Osnovnye podhody k raschetu nalogovoj nagruzki organizacii / E.S. Har'kova // Moya professional'naya kar'era. 2020. T. 1. № 12. S. 209-213.

15. SHestakova, E. V. Optimizaciya nalogov / E.V. SHestakova. - Rostov/n/D. : Feniks, 2019.

16. Ault, H. J. Comparative Income Taxation : A Structural Analysis / H.J. Ault. - New York : Arnold B.J. Aspen Publisher, 2018.

17. Feenstra, R. C. Advanced international trade : theory and evidence / R.C. Feenstra. - Princeton : Princeton University Press, 2018.

18. Paart Van der, D. Subsidies in the EU and Switzerland / D. Van der Paart, N.G. Rene // VAT Monitor. IBFD. 2019. № 2. P. 32-36.

19 URL : http://www.nalog.ru - Federal'naya nalogovaya sluzhba (data obrashcheniya : 01. 03.2021).

20.URL : http://elibrary.ru - Nauchnaya elektronnaya biblioteka (data obrashcheniya: 16.04.2021). 